\title{
The evolution of obesity: from evolutionary advantage to a disease
}

\author{
Keneilwe Malomo ${ }^{1}$ and Ontefetse Ntlholang ${ }^{2 *}$ \\ ${ }^{1}$ Connolly Hospital, Blanchardstown, Dublin 15, Ireland \\ ${ }^{2}$ Department of Geriatric and Stroke Medicine, Beaumont Hospital, Dublin 9, Ireland
}

\begin{abstract}
Obesity is linked to several diseases and reduced life expectancy. The prevalence of this important public health issue is increasing worldwide.

Aim: The aim of this paper is to highlight the evolution of obesity from the Paleolithic era to the present period and promote it as a disease rather than survival advantage as it used to be perceived.

Methods: An overview of the evolution of obesity including from sociocultural perspective throughout history and linking it to metabolic disorders, based on a narrative review of the literature.

Conclusion: Published literature on the history of obesity reveals that obesity has been present all along. There seems to be an acknowledgment of obesity as a disease recently, politically and medically. This acknowledgment would facilitate treatment options and policies aimed at curbing increasing obesity.
\end{abstract}

\section{Introduction}

Obesity is defined as an excessive fat accumulation that may impair health [1]. There are several ways of predicting obesity, the common ones being waist circumference (WC), waist-hip ratio (WHR) and body mass index (BMI). World Health Organization (WHO) defines obesity as a BMI greater than or equal to 30 [1]. It is a common public health issue and the prevalence is increasing worldwide. The global agestandardized prevalence of obesity doubled from $6.4 \%$ in 1980 to $12.0 \%$ [2]. Overall, about $13 \%$ of the world's adult population ( $11 \%$ of men and $15 \%$ of women) was obese in 2016 [1].

This paper will address the evolution of obesity from the Paleolithic era to the present era. It will highlight the presence and perception of obesity in each era. Furthermore, emphasis will be on obesity as a disease from medico-political and socio-cultural perspectives. This is based on a narrative review of available literature.

\section{Paleolithic era}

The Paleolithic Era is a period of prehistory from about 2.6 million years ago to around 10000 years ago [3]. Obesity studies from the Paleolithic era are based on figurines of that time. Paleolithic humans used primitive stone tools and they survived as hunters and gatherers [4]. As nomads, their food source depended greatly on the environment and climate changes. Figurines curved during the Paleolithic era may depict the sociocultural perspectives of the individual population. In this section, we reviewed studies based on the figurines to emphasize the presence of obesity in the paleolithic era.

Pontius [5], described two important terms for use in studying prehistory; heuristic and iconodiagnosis. In simple terms, she suggested the use of experience-based techniques to study and interpret prehistoric art within a medical framework. The author highlighted two types of obesity- gluteal and abdominal. Further emphasis was on the association of abdominal obesity with disease processes and sedentary lifestyle contrary to the gluteal obesity (temporary energy storage) likened to camel's hump [5].

The most famous statue is of 'Venus of Willendorf' dated over 30 000 years ago [6]. It has provided the earliest depictions of obesity [4,7]. This figurine depicts generalized obesity, central adiposity, and large waist circumference. Venus (to the Romans), attributed to representing Aphrodite, the Greek, goddess of love and beauty [8]. Seshadri [5]. postulated that in the hunter-gatherer society that she (Venus) lived in, lower body mass index (BMI) was more common in women with consequent infertility and hence Venus could have been a model for hunter-gatherer women to aspire for, with no chances of ever becoming one.

Another important paper examining obesity in the paleolithic era used photos and/or copies of one hundred statues [9]. Ninety-seven of those studied were females of whom 24 were skinny (mainly young women), 15 were of normal weight, whilst more than half of them (51) were either overweight or very obesity. They found that the figurines examined revealed various types of obesity ranging from belly only, belly and hips, belly and gluteal and hips, belly and hip and gluteal and femora, and diffuse obesity. Furthermore, the paper reported that only 7 statues were in the state of advanced gravidity. We can deduce

*Correspondence to: Ontefetse Ntlholang, Department of Geriatric and Stroke Medicine, Beaumont Hospital, Dublin 9, Ireland, Tel: 0035318093000; E-mail: damaze2002@yahoo.com

Key words: disease, Greco-Roman and Byzantine era, Neolithic era, obesity, paleolithic era

Received: March 12, 2018; Accepted: March 26, 2018; Published: March 30, 2018 
from this study that in the Paleolithic era there might have been double effect malnutrition with underweight, normal weight, overweight, and obesity. We can further deduce that based on the figurines studied there were fewer statues in the state of gravidity and this question the rationale of Venus figurine (obese females) representing the goddess of fertility. In the present time, we know that obesity is associated with the polycystic ovarian syndrome and reduced chance of conception [10].

We can conclude that obesity existed during the Paleolithic era as depicted in arts. The incidence and prevalence at the time are unknown. The presence should be analyzed based on the sociocultural perspectives of people of the time. They depended on hunting and gathering and were prone to the effects of climate change and may be gaining extra fat was survival self-defense at times of famine. Intuitively, it is safe to postulate that due to the sources and nature of food, obesity would not be rampant.

\section{Neolithic era}

The Neolithic Era began around 10,000 B.C. and ended between 4500 and 2000 B.C. in various parts of the world [3]. Neolithic humans discovered agriculture and animal husbandry, which allowed them to settle down in one area [11]. This was the first change in sourcing food. The revolution changed the dynamics of the society from small clusters of hunter-gatherers to a large community of farmers [12]. The change also brought about abundance of food, even though seasonal. Crop production led to increases in carbohydrate-rich diets and changes in dental microbiota [13]. and domestication of cattle (Bos taurus and Bos indicus) from wild aurochsen (Bos primigenius) led to extensive modifications of the diet [14]. The changes in dental microbiota reflect historical dietary changes [13]. Furthermore, Bogaard et al. [15]. using stable isotope showed that early farmers used livestock manure and water to enhance crop yields.

In illustration of the Neolithic era obesity, a female Greek figurine made of clay estimated from $5^{\text {th }}$ Millennium B.C. depicting obesity has been reported [16]. The figurine had visible characteristics of female obesity, protrusion of the abdomen in a broad convexity, legs full, nearly round in section and the size of thighs almost the same as the upper body.

It may be that obesity became more common as agricultural settlements began to take over from hunter-gatherer tribes [15]. The process would need manpower and hence facilitation of large communities to work on the farms and herd animals [12]. The change from exercising all the time (hunt and gather) to periodic work on the farms and sedentary lifestyle and having more food would lead to energy imbalance with built up of positive energy leading to overweight and eventually obesity. The Neolithic revolution would have led to widening the gap in sociocultural groups- the less well-off working for the rich.

\section{Greco-roman and byzantine era}

The Greco-Roman period is from 332 B.C. to 395 A.D. and Byzantine Era began in 395 A.D. with the division of Roman Empire into western and eastern (Byzantine) empires and ended A.D. 641 with Arab conquest [17]. Another source state that the Byzantine Empire ended in 1453 when it was conquered by the Ottoman Turks [18]. Papavramidou et al. [19]. wrote on the views of selected writers of those times in relation to obesity. They reported on the writings of Aulus Cornelius Celsus (circa 25 B.C.), Dioscorides Pedanius (40-90 A.D.), Soranus of Ephesus (98-138 A.D.) whose writings on the subject survived through Caelius Aurelianus (5th c. A.D.), Claudius Aelianus (3rd C. A.D.), Oribasius (324-400 A.D.), Aetius of Amida (circa 450 A.D.), Alexander Trallianus (6th c. A.D.), Paulus Aegineta ( $7^{\text {th }}$ c. A.D.), and Theophilus Protospatharius (9th C. A.D.). It is interesting to note that all selected writers were addressing etiology, manifestations, and treatment of obesity.

They all postulated that a healthy body is a balanced one with moderate thin and fat, balanced temperament and retentive and natural faculties. With regards to obesity, there has to be imbalance i.e. gaining too much fat, having warm or moist temperament against cold temperament and disorder of the retentive faculties. These points address the cause of obesity and point to possible cure by trying to restore the imbalances.

Furthermore, the authors addressed the treatment of obesity by suggesting shifting the ill temperament of the patient to a healthy one and reestablishing the balance of the humors [19]. The treatment options they suggested were all focused on weight loss and include diet, medications, and change in lifestyle among others. Since the Byzantine world is around the Mediterranean, then the diet suggested is thought to be a Mediterranean diet. Mediterranean diet has been shown to reduce the incidence of obesity [20]. and has a protective effect on weight gain and development of type 2 diabetes mellitus [21].

In this section, we have shown that obesity and its management were considered by physicians of the time. It's interesting that in the present era, the focus is on a Mediterranean diet as healthy, i.e. rich in fish, fruits, and vegetables.

\section{The reformation era}

The Reformation era in Europe in 1517 with the publication of Martin Luther's '95 Theses' and ended in 1648 with the Treaty of Westphalia, which ended the Thirty Years' War [22]. It was a period characterized by religious, social and political changes. It was a period when the globalization of the economy and the exchange of foods across continents occurred [23].

Saint Francis de Sales, the Catholic reformer, in the early seventeenth century, had been quoted to allude to overeating as not good for the body, "Eating only to satisfy our appetite is tolerated, but is not in itself praiseworthy, and eating to excess is dangerous" [23]. We can deduce that it might have been about excess eating leading to obesity or corpulence. An example of obesity during the Reformation era includes the Protestant reformer, Martin Luther [24,25]. Portraits of the time also depict obesity, e.g., of Alessandro Del Borro [26], Rubenesque [27], and Henry the VIII [28].

\section{Industrialization and urbanization}

The industrial revolution of 1850's led to easy accessibility to processed foods e.g. white sugar and flour [29]. Industrialisation led to a shift towards added sugars and high-fat diet in a heterogeneous pattern depending on the region and culture. Simultaneously, the occupations required less energy to be expended and the new technologies allowed those in each occupation to engage in increasingly sedentary work [30]. The technologies included packaging, refrigeration, cookers, fire, and electricity among others i.e. food technology to make food easily accessible [30].

Transportation changed from walking and horse-drawn vehicles to trains, cars, electric scooters, and buses for rapid access. Transportation of goods involved the use of trucks and lorries and most notably rail networks [29]. These changes would lead to energy preservation which in turn would be converted to fat and lead to obesity. 
Urbanization described as a shift from rural to urban dwelling also had an impact on weight. In urban areas, there is limited engagement in sports, and easy access to television and associated media advertising high fat, high carbohydrates food, and hence energy imbalance leading to overweight and/or obesity [30]. Having stated that, efforts to reduce overweight and hypertension and their health sequelae should address the dietary changes and reductions in physical activity that have occurred in both urban and rural populations [31]. and brought about by rural-urban shift.

In China for an example, there has been a rapid growth of population dwelling in urban areas. The economic opportunities are a strong pull factor stimulating migration and the effect is to provide a large labour pool for productive activities in urban areas [31]. According to Popkin, 2008 [32], the rapid decline in energy expenditure of the population, linked with the enormous shift towards a diet with more energy density from edible oils and animal source foods, have resulted in a rapid increase in the distribution of the body mass index (BMI) of the Chinese population, particularly adults.

In this section, we have shown that industrialization and urbanization brought about high energy/ high-fat diet and reduced energy expenditure. The consequence of this would be increased weight.

\section{Sociocultural perspective}

Social and cultural perspectives of body size of different populations/ regions dictate the body weight of those populations. A person's culture permeates every aspect of their life, including how they think about fatness and thinness, and all other facets of living in the world [33].

\section{Chinese}

Chinese diet like other Asian countries has shifted from more traditional plant-based diet to westernized, highly processed diet [34]. The money elasticity for the demand for edible oil rose significantly between 1989 and 1993 and was positive at all income values [30]. These high calorie/ high-fat diets have potential to increase incidence and prevalence of overweight and obesity.

Guldan [34], reported that Asian childhood overweight dietary patterns include snacking and eating out; consumption of fast food, sweetened beverages, and excessive meat; unhealthy macronutrient energy proportions; and a preference for refined grains. Furthermore, overweight or obese adolescents tended to view TV programs and become less physically active [35]. Using data from China Health and Nutrition Survey, a longitudinal survey from 1989 to 1997, Luo et al. [36], reported that the prevalence of obese children aged 2-6 years increased from $1.5 \%$ to $12.6 \%$ in urban areas and prevalence of overweight increased from 14.6 to $28.9 \%$ in the same period.

Changes in social status have resulted in a rapid increase in the distribution of the body mass index (BMI) of the Chinese population, with adult male overweight status tripling and female overweight status doubling between 1989 and 2000 [32]. Furthermore, Popkin [32], reported that more than $1.2 \%$ of the Chinese adult male population have become overweight or obese each year over the past decade while among adult men from Australia, the U.K., and the United States, the annual rate of increase was slightly less. These changes could at least be attributed to a rapid decline in energy expenditures and high caloric/ high-fat diet.

\section{Sub-Saharan Africa}

In Africa, with special reference to sub-Saharan Africa, social epidemiology reveals that females (sex) and women (gender) regard plumpness as a sign of beauty, fertility, and well-being [37,38]. This social depiction is more on ethnic lineages [39]. When a female is due to get married is fattening to prepare her for pregnancy, breastfeeding and social status as a married woman in the community [39]. These cultural connotations lead to females being more overweight and/or obese in this part of Africa.

The expectation of certain cultures of women in the society to be overweight/obese precludes the concerned society to notice or appreciate obesity as a chronic disease but rather as a sign of beauty, pride, health, and wellness [38]. Culture as a changing phenomenon is influenced by national and international media, occupations, psychosocial factors and importantly the advent of modeling industry that might have led to double effect malnutrition- thinness and fatness in the same communities. Holdsworth et al, 2004 [37]. found that Senegalese women preferred overweight BMI to normal BMI and concluded that the term 'overweight' made little sense to those Senegalese women and could have important implications for developing public health policies. Overweight and obesity are on the rise in sub-Saharan Africa with women being disproportionately affected compared to men [40].

\section{Western countries}

In the United States and other western countries, there is an increased trend of consuming meals outside of the home, however, the diet tends to have higher fat/higher calories and less healthy food [41]. Stewart et al. [42], reported that almost three-quarters of people surveyed usually eat out at least once a week and the pattern was attributable to growing consumer demand for a variety of foods, convenience, and entertainment. Furthermore, a systematic review and meta-analysis revealed the low cost of high calories/ high-fat diet as compared to a healthy one [43]. A data from a population-based study showed that a high adherence to the Mediterranean Diet Score and Healthy Eating Index, both inversely associated with BMI and obesity, led to higher monetary costs as compared to a low adherence [44].

Advertising of high calorie/ high-fat diet could promote a culture of unhealthy eating [41]. The target mainly is children's programmes [45]. Advertising of junk food and fast food increases children's requests for those particular foods and products, snacking increases while watching TV or movies, and late-night screen time may interfere with getting adequate amounts of sleep, which is a known risk factor for obesity [46]. Moreover, the western culture towards food is one of excess, with ever-increasing portion sizes, instant gratification and the 'more for less' mindset [47].

Studies of acculturation showed that when people move from one culture to another, they lose their original culture towards diet $[48,49]$. Western culture associate obesity with social status among men but place increasing pressure on women to be thin leading to gender disparities [49]. These sociocultural factors affect gender disparities in excess weight gain in developed countries such that more women than men are obese, whereas more men than women are overweight [49].

\section{Obesity as a disease}

Cheng [7], reported that obesity as a risk factor for cardiovascular disease was recognized by Hippocrates (460-c375 B.C.) and further mentioned that Hippocrates pointed out the shortened life expectancy of the obese versus slender. Hippocrates condemned overeating and linked it to cerebrovascular disease: "A city that lies exposed to the hot winds. Most of the inhabitants have a rather flabby physique. When they are more than fifty years old they are paralyzed by catarrhs supervening from the brain [50]. 
Galen (c129-210 A.D.), whose work was somehow based on Hippocrates work also supported the notion of reaching a balance to keep the body healthy [51]. Galen proposed six factors, air and environment; food (diet) and drink; sleep and wake; motion (exercise) and rest; retention and evacuation; and passions of the mind (emotions) and recommended that these factors should be used in moderation since too much or too little would put the body in imbalance and lead to disease or illness [51].

Papavramidou et al. [19], reported on Greco-Roman and Byzantine era's view of obesity. They reported on 10 writers of that era, from Aulus Cornelius Celsus (circa 25 B.C.) to Theophilus Protospatharius ( $9^{\text {th }}$ C. A.D.), whose writings focused on etiology, presentation, and management of obesity. They all described a healthy body as the one in absolute balance i.e. balance in humors, balance in temperament, balance in thin and fat and natural faculties, with imbalance leading to either underweight or overweight/obese and management being restoration and maintenance of the imbalances.

The Gulstonian Lectures in 1850 [52], focused on obesity as a disease. In the lecture Chambers described the etiology, presentation, and management with a focus on physiology and pathophysiology. The letter highlighted that obesity was common, and a disease but received little attention.

Obesity was brought more into the limelight by the insurance industry [4]. due to its link with increased mortality by actuarial studies in the twentieth century. Eknoyan [4], further reported that by 1930s the medical profession made a total about-face on the desirability of excess 'flesh' and accepted fat as a health problem after analysis of Metropolitan Life Insurance Company data in 1920s for differential mortality by weight. By the 1920s, insurance companies were already charging higher premiums for life insurance coverage to persons with excess body weight, based on their own actuarial data on mortality rates of obese people [53].

James [54], reported that obesity was already classified as a disease with the formation of World Health Organization (WHO) in 1948. Obesity and its associated co-morbidities have been recognized as diseases for over half a century. It is worth noting that since then obesity remained neglected probably due to lack of political and medical will. It is not often realized that the World Assembly delegations agreeing new policies are essentially controlled by the foreign services of the member states and they often overturn the views of their own Ministries of Health if there are strong economic arguments from the Trade or Agriculture departments [54].

In the United States, earlier reports of the problem of obesity surfaced in 1966 by US Department of Health followed by the US Senate's Select Committee on Nutrition report on 'Nutrition and Health' in 1975, warning of the alarming increase in the prevalence of 'diseases of over-abundance' [53].

In June 2013, American Medical Association classified obesity as a disease [55]. Furthermore, in November 2013, The American Heart Association, American College of Cardiology and The Obesity Society, released guidelines that doctors should consider obesity as a disease and treat obese patients for weight loss actively [56]. The guidelines also recommended weight loss for some overweight people e.g. individuals with a BMI of 25 to 29.9 , and one risk factor, such as hypertension or hypertriglyceridemia.

\section{Conclusion}

We have shown that obesity has been recognized from the Paleolithic era up to the present. Obesity as a disease was first described by Hippocrates, followed by physicians of the Greco-Roman and Byzantine eras. Furthermore, in 1920's the Insurance Companies, in 1948 World Health Organisation and in 2013 both American Medical Association and The American Heart Association, American College of Cardiology and The Obesity Society recognized obesity as a disease. This acknowledgment would facilitate treatment options and policies aimed at curbing increasing obesity.

\section{References}

1. http://www.who.int/news-room/fact-sheets/detail/obesity-and-overweight

2. Stevens GA, Singh GM, Lu Y, Danaei G, Lin JK, et al. (2012) National, regional, and global trends in adult overweight and obesity prevalences. Popul Health Metr 10: 22. [Crossref]

3. http://www.diffen.com/difference/Neolithic_vs_Paleolithic

4. Eknoyan G (2006) A history of obesity, or how what was good became ugly and then bad. Adv Chronic Kidney Dis 13: 421-427. [Crossref]

5. Pontius AA (1986) Stone-age art "Venuses" as heuristic clues for types of obesity: contribution to "iconodiagnosis". Percept Mot Skills 63: 544-546. [Crossref]

6. http://www.the-art-minute.com/the-venus-of-willendorf-it-doesnt-get-any-older-thanthis/

7. Cheng TO (2006) Obesity, Hippocrates and Venus of Willendorf. Int J Cardiol 113: 257. [Crossref]

8. Seshadri KG (2012) Obesity: A Venusian story of Paleolithic proportions. Indian J Endocrinol Metab 16: 134-135. [Crossref]

9. Jozsa LG1 (2011) Obesity in the paleolithic era. Hormones (Athens) 10: 241-244 [Crossref]

10. Kuchenbecker WK1, Groen H, van Asselt SJ, Bolster JH, Zwerver J, et al. (2011) In women with polycystic ovary syndrome and obesity, loss of intra-abdominal fat is associated with resumption of ovulation. Hum Reprod 26: 2505-2512. [Crossref]

11. http://history-world.org/neolithic1.htm

12. http://faculty.citadel.edu/frank.karpiel/class $02 \% 20$ farmherd.pdf

13. Sajantila A (2013) Major historical dietary changes are reflected in the dental microbiome of ancient skeletons. Investig Genet 4: 10.

14. Beja-Pereira A, Caramelli D, Lalueza-Fox C, Vernesi C, Ferrand N, et al. (2006) The origin of European cattle: evidence from modern and ancient DNA. Proc Natl Acad Sci US A 103: 8113-8118. [Crossref]

15. Bogaard A, Fraser R, Heaton TH, Wallace M, Vaiglova P, et al. (2013) Crop manuring and intensive land management by Europe's first farmers. Proc Natl Acad Sci U S A 110: 12589-12594. [Crossref]

16. Christopoulou-Aletra H, Papavramidou N, Pozzilli P (2006) Obesity in the Neolithic era: a Greek female figurine. Obes Surg 16: 1112-1114. [Crossref]

17. http://www.thebanmappingproject.com/resources/timeline_10.html

18. http://history-world.org/byzantine_empire.htm

19. Papavramidou N, Christopoulou-Aletra H (2007) Greco-Roman and Byzantine views on obesity. Obes Surg 17: 112-116. [Crossref]

20. Mendez MA, Popkin BM, Jakszyn P, Berenguer A, Tormo MJ, et al. (2006) Adherence to a Mediterranean diet is associated with reduced 3-year incidence of obesity. J Nutr 136: 2934-2938. [Crossref]

21. Schröder H (2007) Protective mechanisms of the Mediterranean diet in obesity and type 2 diabetes. J Nutr Biochem 18: 149-160. [Crossref]

22. http://www.history.com/topics/reformation

23. Albala K (2013) Food: A Cultural Culinary History. Chantilly, Virginia: The Great Courses. pp: 127- 33 .

24. Iversen OH (1996) Martin Luther's somatic diseases. A short life-history 450 years after his death. Tidsskr Nor Laegeforen 116: 3643-3646. [Crossref] 
25. Takigami T (2011) Medical history of Martin Luther. Nihon Ishigaku Zasshi 57: 433449. [Crossref]

26. http://men-in-full.livejournal.com/16458.html

27. http://historicalromanceuk.blogspot.ie/2015/03/rubenesque.html

28. Chalmers CR, Chaloner EJ (2009) 500 years later: Henry VIII, leg ulcers and the course of history. J R Soc Med 102: 514-517. [Crossref]

29. Clayton P, Rowbotham J (2009) How the mid-Victorians worked, ate and died. Int $J$ Environ Res Public Health 6: 1235-1253. [Crossref]

30. Popkin BM (2001) The nutrition transition and obesity in the developing world. $J$ Nutr 131: 871S-873S. [Crossref]

31. Gong P, Liang S, Carlton EJ, Jiang Q, Wu J, et al. (2012) Urbanisation and health in China. Lancet 379: 843-852. [Crossref]

32. Popkin BM (2008) Will China's nutrition transition overwhelm its health care system and slow economic growth? Health Aff (Millwood) 27: 1064-1076. [Crossref]

33. Sobal J (2001) International Textbook of Obesity: John Wiley \& Sons Ltd.

34. Guldan GS (2010) Asian children's obesogenic diets-time to change this part of the energy balance equation? Res Sports Med 18: 5-15. [Crossref]

35. von Deneen KM, Wei Q, Tian J, Liu Y (2011) Obesity in China: what are the causes? Curr Pharm Des 17: 1132-1139. [Crossref]

36. Luo J1, Hu FB (2002) Time trends of obesity in pre-school children in China from 1989 to 1997. Int J Obes Relat Metab Disord 26: 553-558. [Crossref]

37. Holdsworth M, Gartner A, Landais E, Maire B, Delpeuch F (2004) Perceptions of healthy and desirable body size in urban Senegalese women. Int $J$ Obes Relat Metab Disord 28: 1561-1568. [Crossref]

38. Puoane T, Tsolekile L, Steyn N (2010) Perceptions about body image and sizes among Black African girls living in Cape Town. Ethn Dis 20: 29-34. [Crossref]

39. Brewis AA (2011) Obesity: cultural and biocultural perspectives. New Brunswick, N.J. Rutgers University Press. Pp: 99- 106.

40. BeLue R, Okoror TA, Iwelunmor J, Taylor KD, Degboe AN, et al. (2009) An overview of cardiovascular risk factor burden in sub-Saharan African countries: a socio-cultural perspective. Global Health 5: 10. [Crossref]

41. Swinburn BA, Caterson I, Seidell JC, James WP (2004) Diet, nutrition and the prevention of excess weight gain and obesity. Public Health Nutr 7: 123-146. [Crossref]
42. Stewart H, Blisard, N, Jolliffe, D (2006) Let's Eat Out: Americans Weigh Taste, Convenience, and Nutrition. Economic Research Service/USDA, Service ER; 200619 Contract No.: EIB 19.

43. Rao M, Afshin A, Singh G, Mozaffarian D (2013) Do healthier foods and diet patterns cost more than less healthy options? A systematic review and meta-analysis. BMJ Open 3: e004277. [Crossref]

44. Schröder H, Marrugat J, Covas MI (2006) High monetary costs of dietary pattern associated with lower body mass index: a population-based study. Int $J$ Obes (Lond) 30: 1574-1579. [Crossref]

45. Powell LM, Szczypka G, Chaloupka FJ, Braunschweig CL (2007) Nutritional content of television food advertisements seen by children and adolescents in the United States. Pediatrics 120: 576-583. [Crossref]

46. Council on Communications and Media, Strasburger VC (2011) Children, adolescents, obesity, and the media. Pediatrics 128: 201-208. [Crossref]

47. [No authors listed] (2010) Obesity: A Public Health Crisis. Pp: 1-22.

48. Holmboe-Ottesen G, Wandel M (2012) Changes in dietary habits after migration and consequences for health: a focus on South Asians in Europe. Food Nutr Res 56. [Crossref]

49. Kanter R, Caballero B (2012) Global gender disparities in obesity: a review. Adv Nutr 3: 491-498. [Crossref]

50. Cheng TO (2001) Hippocrates and cardiology. Am Heart J 141: 173-183. [Crossref]

51. Berryman JW (2012) Motion and rest: Galen on exercise and health. Lancet 380: 210211. [Crossref]

52. Chambers TK (1993) The Gulstonian Lectures. 1850. Obes Res 1: 57-84. [Crossref]

53. Caballero B, Wang Y (2006) Commentary: Obesity and mortality--light at the end but still a long tunnel. Int J Epidemiol 35: 21-22. [Crossref]

54. James WP (2008) WHO recognition of the global obesity epidemic. Int J Obes (Lond) 32: S120-S126. [Crossref]

55. http://www.ama-assn.org/ama/pub/news/news/2013/2013-06-18-new-ama-policiesannual-meeting.page

56. Jensen MD, Ryan DH, Apovian CM, Ard JD, Comuzzie AG, et al. (2014) 2013 AHA ACC/TOS guideline for the management of overweight and obesity in adults: a report of the American College of Cardiology/American Heart Association Task Force on Practice Guidelines and The Obesity Society. Circulation 129: S102-S138. [Crossref]

Copyright: (C2018 Malomo K. This is an open-access article distributed under the terms of the Creative Commons Attribution License, which permits unrestricted use, distribution, and reproduction in any medium, provided the original author and source are credited. 